within the same tumor. ${ }^{2}$ It is generally accepted that these tumors originate as a primary epithelial malignancy from which a subset of cells then undergoes dedifferentiation into sarcomatous cells. ${ }^{1,2}$ This theory is supported by the frequent finding of a transition zone between the 2 cell populations. ${ }^{2,4}$ Previous theories of 2 simultaneously occurring malignancies (collision tumor) or a common origin from a single pleomorphic cell population have fallen out of favor. ${ }^{2}$

The epithelial component is usually squamous cell carcinoma, but adenocarcinoma can also occur. ${ }^{4}$ Fibrosarcoma is the most common sarcomatous component, although rhabdomyosarcoma, chondrosarcoma, and osteosarcoma (as occurred in our patient) have also been described. ${ }^{2,4}$ The sarcomatous cells stain for vimentin, whereas the epithelial cells stain for cytokeratin, ${ }^{4}$ although it has been reported that the sarcomatous cells might stain for cytokeratin and the epithelial cells for vimentin. ${ }^{4}$ Importantly, results of S100 protein staining are negative, thus differentiating carcinosarcoma from stromal tumor and an important diagnostic consideration. $^{3}$

Clinically, carcinosarcomas are characterized by short doubling time (around 2 months) and rapid growth. ${ }^{1}$ They are typically large at presentation (mean, 6-7 cm) and polypoid. ${ }^{2}$ Oat cell carcinoma, squamous cell carcinoma, and adenocarcinoma might also present as bulky polypoid tumors of the esophagus, although much more rarely. ${ }^{5}$ Endoscopic biopsy specimens show only the epithelial component in close to two thirds of cases. ${ }^{2}$ In spite of their propensity to cause symptoms earlier because of their large size and the fact that more than $80 \%$ of tumors are limited to the submucosa or muscularis propria at presentation, ${ }^{2,4,5}$ these tumors might behave aggressively, and thus radical resection in the form of esophagectomy is advocated. ${ }^{1,2}$ Local resection through an esophagotomy has been described in frail patients thought to represent a high operative risk, with occasional long-term survival. ${ }^{2}$ Chemotherapy and radiotherapy have rarely been reported, and their efficacy is unclear. ${ }^{2}$ Long-term prognosis is thought to be similar to that of pure squamous cell carcinoma of the esophagus. ${ }^{5}$

\section{References}

1. Hung JJ, Li AF, Liu JS, Lin YS, Hsu WH. Esophageal Carcinosarcoma with basaloid squamous cell carcinoma and osteosarcoma. Ann Thorac Surg. 2008;85:1102-04.

2. Iascone C, Barreca M. Carcinosarcoma and pseudosarcoma of the esophagus: two names, one disease-comprehensive review of the literature. World J Surg. 1999; 23:153-7.

3. Kimura H, Konishi K, Kawamura T, Nojima N, Satou T, Maeda K, et al. Esophageal sarcomas: report of three cases. Dig Surg. 1999;16:244-7.

4. Ziauddin MF, Rodriguez HE, Quiros ED, Connolly MM, Podbielski FJ, et al. Carcinosarcoma of the esophagus_-pattern of recurrence. Dig Surg. 2001;18:216-8.

5. Olmsted WW, Lichtenstein JE, Hyamus VJ. Polypoid epithelial malignancies of the esophagus. AJR Am J Roentgenol. 1983;140:921-5.

\title{
Pulmonary artery ligation with lung preservation in Behcet disease: Report of a case with prolonged survival
}

\author{
Rizwan Attia, MRCS, John Reidy, FRCR, David D’Cruz, FRCP, and Loïc Lang-Lazdunski, MD, PhD, \\ FRCS, London, United Kingdom
}

Rupture of a pulmonary artery (PA) aneurysm remains a leading cause of death in patients with Behcet disease. ${ }^{1}$ We present a case of successful PA ligation and lung preser-

\footnotetext{
From the Department of Thoracic Surgery, Departments of Rheumatology and Radiology, Guy's \& St Thomas' Hospital, London, United Kingdom. Disclosures: None.

Received for publication Oct 20, 2008; revisions received July 1, 2009; accepted for publication July 13, 2009; available ahead of print Sept 11, 2009.

Address for reprints: Loic Lang-Lazdunski, MD, PhD, FRCS, Department of Thoracic Surgery, Guy's Hospital, Great Maze Pond, London SE1 9RT, United Kingdom (E-mail: loic.lang-lazdunski@gstt.nhs.uk).

J Thorac Cardiovasc Surg 2010;139:e93-5

$0022-5223 / \$ 36.00$

Copyright (c) 2010 by The American Association for Thoracic Surgery

doi:10.1016/j.jtcvs.2009.07.033
}

vation with prolonged survival in a patient with Behcet disease and bilateral PA aneurysm.

\section{CLINICAL SUMMARY}

A 36-year-old white man with bilateral PA aneurysms and known Behcet disease had a massive hemoptysis. Medical history included oral and genital ulcerations, pulmonary embolus, left lower lobe infarction, and iliac vein thrombosis after cardiotomy for suspected tricuspid valve endocarditis. The patient was receiving steroids, immunosuppressants, and warfarin. Five months previously, he had coil embolization of an expanding pseudoaneurysm of a basal segmental branch of the right PA, and a covered stent was placed into this arterial branch (Figure 1). 

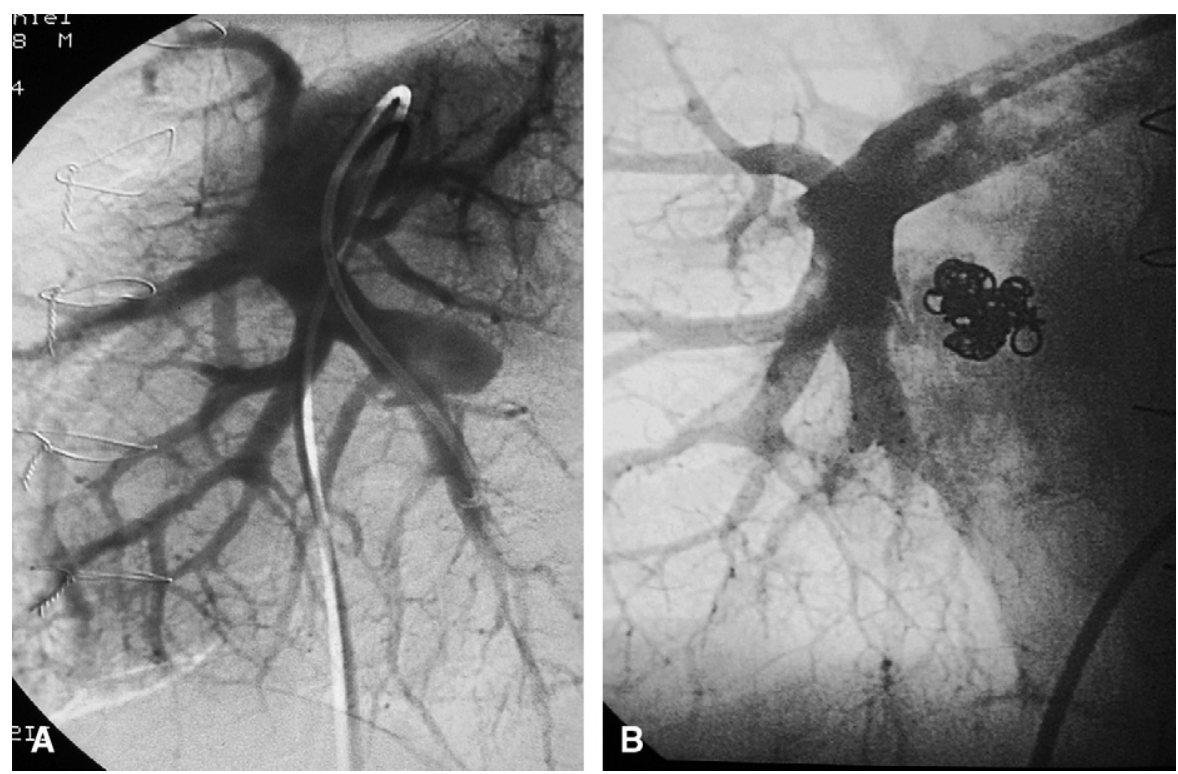

FIGURE 1. Left, Pulmonary angiogram showing a pseudoaneurysm involving a basal segmental branch of the right lower pulmonary artery. Right, Pulmonary angiogram after successful coil embolization.

The patient was admitted into the critical care unit, intubated, and ventilated for ongoing bleeding and respiratory distress. A computed tomographic scan of the chest showed consolidation of the left lower lobe and a large left PA aneurysm at the hilum ( $>70 \mathrm{~mm}$ diameter). Bronchoscopic examination demonstrated bleeding coming from the left main bronchus. Emergency left thoracotomy revealed extensive adhesions between the left lower lobe, diaphragm, and lower chest wall. A large inflammatory aneurysm was found involving all of the left lung segmental branches. It seemed unsafe to perform a pneumonectomy or an aneurysmorrhaphy. The PA was ligated at the hilum and the thoracotomy incision closed. The patient made a good recovery and was discharged after 16 days. He was prophylactically administered cefuroxime and met- ronidazole during his entire hospital stay. Clinically insignificant episodes of hemoptysis have occurred on and off since the operation. Four years postoperatively, the patient remains active despite grade II dyspnea, receiving prednisolone, methotrexate, and daily enoxaparin. Chest computed tomography demonstrates no evidence of infection or necrosis in the left lung (Figure 2).

\section{DISCUSSION}

Behcet disease is a multisystem disorder characterized by vasculitis, first described by Behcet in 1937. The prevalence of PA aneurysm in Behcet disease is around 30\%, and 93\% of patients with PA aneurysms have hemoptysis. ${ }^{1}$ Medical treatment with immunosuppressants and interventional procedures are now recognized as the first-line options. ${ }^{1}$

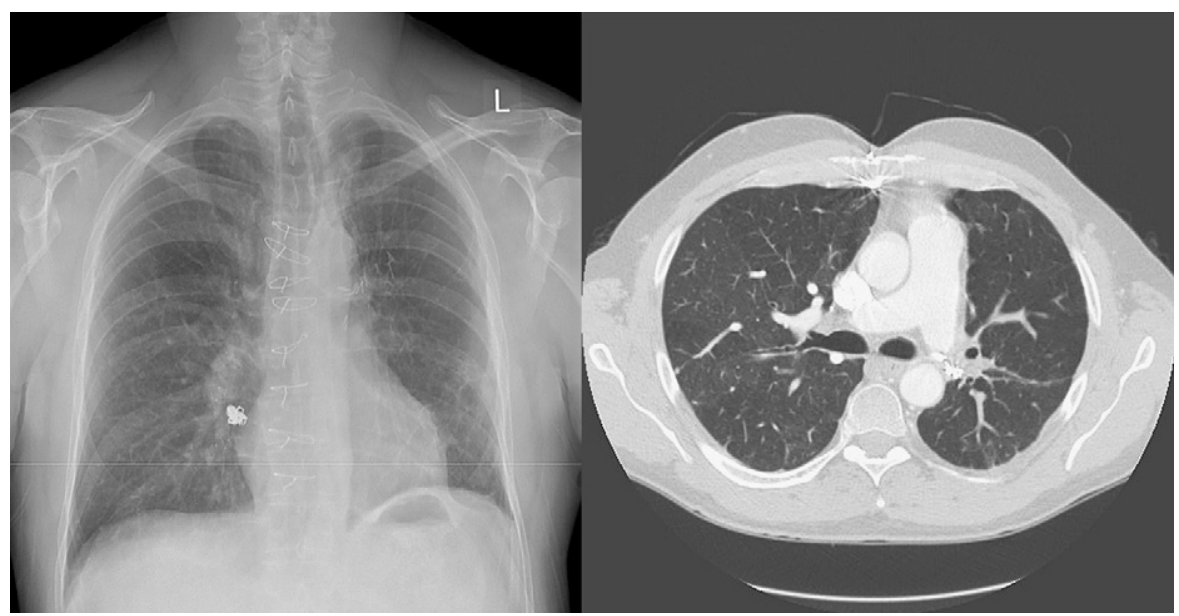

FIGURE 2. Chest $x$-ray film and computed tomographic scan performed at 4 years. The pulmonary ligature is visible at the left hilum. There is no sign of repeat hemoptysis, lung necrosis, or infection on either side. 
Surgery is usually reserved for fit patients who fail to respond to medical therapy and interventional procedures. ${ }^{1}$ However, lung resection performed in this setting carries a high-risk of mortality-especially when the operation is undertaken for acute massive bleeding-and may represent only a temporary solution. ${ }^{1}$ A recent review of patients with Behcet disease and pulmonary involvement showed that $50 \%$ of patients died within 10 months of hemoptysis. ${ }^{2}$ However, it is widely established that long-term immunosuppressant therapy may sometimes resolve PA aneurysms. ${ }^{1}$ At present, the 1-year and 5-year survivals of patients with hemoptysis owing to PA aneurysm are 57\% and $39 \%$, respectively. ${ }^{1}$ Surgery in Behcet disease has involved pneumonectomy, lobectomy, aneurysmorrhaphy, and replacement of the PA with reimplantation of segmental branches. ${ }^{3}$

Controlling hemorrhage by performing a pneumonectomy, in the presence of extensive adhesions in immunosuppressed patients with severe chronic inflammation, is challenging. These patients represent a previously unreported high-risk group for pneumonectomy. In the present case, the original plan was to reconstruct the left PA with polytetrafluoroethylene. However, the extensiveness of the aneurysm and appearance of the friable and fragile tissues prevented such a repair, and the surgeon believed it was safer to ligate the PA at the hilum to stop the hemorrhage. In addition, the risk of secondary bronchopleural fistula and empyema is probably very high in this group of patients who are on a long-term regimen of steroid and immunosuppressive therapy. Empyema and bronchopleural fistula would have been fatal in this patient.
PA ligation with lung preservation was reported in the 1950s in experimental animal models and in humans for bronchiectasis, tuberculosis, and unresectable lung cancer. ${ }^{4}$ The lack of recent clinical reports suggests the procedure may have been largely abandoned in clinical practice.

Pulmonary infarction or necrosis after PA ligation is rare inasmuch as bronchial arteries or collaterals may contribute to an alternative blood supply. It has been shown in a mouse model that the intercostal vasculature in proximity to the ischemic lung does proliferate and infiltrate the lung within days after the ischemic event. ${ }^{5}$

\section{CONCLUSION}

This case shows that it is possible to ligate the PA and leave the lung in situ in cases in which it is unsafe to perform a pneumonectomy. We think this may represent a life-saving procedure, which could be used on occasion by thoracic surgeons when there is no other safe option for the control of pulmonary hemorrhage.

\section{References}

1. Uzun O, Akpolat T, Erkan L. Pulmonary vasculitis in Behcet disease: a cumulative analysis. Chest. 2005;127:2243-2253.

2. Hamuryudan V, Yurdakul S, Moral F, Numan F, Tüzün H, Tüzüner N, et al. Pulmonary arterial aneurysms in Behcet's syndrome: a report of 24 cases. Br J Rheumatol. 1994;33:48-51.

3. Cebi N, Johannes F, Botsios S, Walterbusch G. Intraparenchymal replacement of the left pulmonary artery with implantation of segmental arteries in a 26-year old patient. J Thorac Cardiovasc Surg. 2003;126:2074-2077.

4. Reyes P, Meich G, Witz JP. Intrapericardial ligation of the right pulmonary artery without lung resection for severe haemoptysis: a complication of an inoperable bronchial neoplasm. Poumon Coeur. 1961;17:297-305 (In French).

5. Wagner EM, Petrache I, Schofield B, Mitzner W. Pulmonary ischemia induces lung remodelling and angiogenesis. J Appl Physiol. 2006;100:587-593. 